\title{
Estudo multicêntrico da mortalidade por homicídios em países da América Latina
}

\author{
Multicentric study of deaths by homicide \\ in Latin American countries
}

Edinilsa Ramos de Souza ${ }^{1}$

André Nascimento de M elo ${ }^{2}$

Juliana Guimarães eSilva ${ }^{1}$

Saúl Alonso Franco ${ }^{3}$

M arcio Alazraqui ${ }^{4}$

Guillermo Julián González-Pérez ${ }^{5}$

${ }^{1}$ Centro Latino Americano de Estudos de Violência e Saúde Jorge Careli, da Escola N acional de Saúde Pública Sergio Arouca, Fundação Oswaldo Cruz. Avenida Brasil 4036/700 M anguinhos. 21040-361 Rio deJaneiro RJ. edinilsaramos@gmail.com ${ }^{2}$ Escola N acional de Saúde Pública Sergio Arouca, Fundação Oswaldo Cruz. ${ }^{3}$ Universidade $\mathrm{N}$ acional de Colômbia.

${ }^{4}$ Instituto de Salud Colectiva, Universidad Nacional deLanús ${ }^{5}$ Centro deEstudios en Salud, Población y Desarrollo Humano, Centro Universitario de Ciencias dela Salud, Universidad de Guadalajara.
Abstract This article is a descriptive epidemiological study of deaths by homicidein Latin American countries (Argentina, Brazil, Colombia and M exico) from 1990 to 2007. D eaths due to external causes and homicides, as codified in the $9^{\text {th }}$ and $10^{\text {th }}$ revisions of the International Classification of Diseases/ICD, were analyzed considering sex, age and manner of assault. The numbers, ratios and adjusted rates for deaths by homici de are presented. A linear regression model was used to ascertain the trend of homiciderates by age group. During the period, 4,086,216 deaths from external causes and 1,432,971 homicides were registered in these countries. Deaths from external causes rose $54.5 \%$ in Argentina but fell in the other countries (37\% in M exico, $31.8 \%$ in Colombia, and $8.1 \%$ in Brazil). The ratio for deaths by homicide for both sexes was 9.1 in Colombia, 4.4 in Brazil and 1.6 in M exico, using the Argentinian rates as a benchmark. There were differences in the evolution of homicide rates by age and sex in the countries: the rate rose in Brazil and fell in Colombia for all age groups. The need to prioritize young males in public policies related to health care and prevention is stressed, as well as the need for the region to adopt inclusive policies and broaden and consolidate democracy and the rights of inhabitants.

Key words Homicide, External causes, Violence, Latin America
Resumo Realizou-se um estudo epidemiológico descritivo da mortalidade por homicídios em países da América Latina (Argentina, Brasil, Colômbia e M éxico) de 1990 a 2007. A nalisam-se óbitos por causas externas e homicídios, codificados nas 9a. e 10a. revisões da Classificação Internacional de D oenças/CID, considerando-sesexo, faixa etária e meio usado na agressão. A presentam- se números, proporções e taxas ajustadas de mortalidade por homi cídios. U sou-se o modelo de regressão linear na tendência das taxas de homicídios por grupos etários. No período, os países contabilizaram 4.086.216 mortes por causas externas e 1.432.971 homicídios. $\mathrm{N}$ a Argentina as causas externas cresceram $54,5 \%$, mas diminuíram nos demais ( $37 \%$ no M éxico; 31,8\% na Colômbia e8,1\% no Brasil). As razões de mortalidade por homicídios para ambos os sexos foram de 9,1 na Colômbia, 4,4 no Brasil e 1,6 no M éxico, tomando-se as taxas da Argentina como referência. A evolução das taxas de homicídios por faixa etária e sexo mostrou-se distinta nos países: em todos os grupos etários foi crescente no Brasil e decrescente na Colômbia. Destaca-se a necessidade de se priorizar os jovens do sexo masculino nas políticas públicas de atenção e prevenção e da região adotar políticas inclusivas, ampliar e consolidar sua democracia e os direitos dos seus habitantes.

Palavras-chave Homicídio, Causas externas, Violência, América Latina 
Introdução

Enquanto sintoma e expressão de problemas sociais, a violência coloca questões para a agenda pública dos distintos setores das sociedades contemporâneas. Por suas repercussões em todos os âmbitos da vida dos indivíduos, grupos enações, como pela magnitude e fortes impactos físicos epsicológicos constitui um grave problema e grande desafio para o setor saúde.

O homicídio, indicador universal da violência social, é definido para o setor saúde como morte por agressão independente da sua tipificação legal, e é o principal responsável pelos elevadosíndices de mortalidade da população mundial ${ }^{1,2}$. No ano 2000, ocorreram 1.659 mil óbitos relacionados à violência no mundo, dos quais $31,3 \%$ foram por homicídios, cuja taxa foi $8,8 /$ 100 mil habitantes².

Como ocorre em relação a outros agravos, os homicídios se distribuem de forma heterogênea entre as regiões e continentes. A América Latina é a região com as mais elevadas taxas de mortalidade por esses eventos (19,9/100 mil hab.), seguida pelo Caribe (16,3/100 mil hab.), África (10,1/ 100 mil hab.), América do Norte (5,6/100 mil hab.), Ásia (2,1/100 mil hab.), Oceania (1,3/100 mil hab.) e Europa (1,2/100 mil hab.) em 20023.

Nos anos 2000, entre os quinze países com as maiores taxas de mortalidade por homicídios no mundo, dez são latino americanos. El Salvador (57,3/100 mil hab. em 2006), Colômbia (42,8/ 100 mil hab. em 2006), Venezuela $(36,4 / 100 \mathrm{mil}$ hab. em 2007) e Guatemala (34,5/100 mil hab. em 2006) encabeçam a lista. 0 Brasil ocupa a $15^{2}$ posição com a taxa de 26,4/100 mil habitantes, em 2008, e o M éxico, com taxa de 7,9/100 mil habitantes, em 2007, ocupa o 220 lugar ${ }^{4}$.

M esmo os países com as menores taxas de homicídio na América Latina, situam-seem posições intermediárias quando comparados ao contexto mundial. A Argentina, por exemplo, que apresenta a menor taxa de homicídios da região (4,3/100 mil hab. em 2007), encontra-se na 39a. posição no cenário internacional, e se insere no grupo dos países com taxas moderadas, acima dos países da Europa ou da O ceania com cerca de 2 homicídios por 100 mil habitantes 5 . E a arma de fogo é o mecanismo mais usado para perpe trá-lo $0^{6-11}$.

Mundialmente e na região latina, no perfil epidemiológico da mortalidade por homicídios se observa o predomínio de pessoas jovens, do sexo masculino, negras ou descendentes dessa raça/etnia, pertencentes ao estrato socioeconô- mico menos favorecido e com baixo nível de escolaridade ${ }^{6}$. Dos 520 mil homicídios registrados no mundo pela Organização Mundial de Saúde, em 2000, $77 \%$ incidiram sobre pessoas do sexo masculino, cujas taxas foram mais de três vezes superiores (13,6/100 mil hab.) às do sexo feminino (4,0/100 mil hab.). Os homens jovens de 15 a 29 anos apresentam o maior risco de morrer por homicídio no mundo (19,4/100 mil hab.) $)^{2}$. A arma de fogo é o mecanismo mais usado nas mortes por homicídios ${ }^{6-11}$.

Diante da magnitude e impacto dos homicídiosna América Latina, esteartigo tem por obje tivo analisar a mortalidade por esses eventos em países da região, entre 1990 e2007, buscando identificar tendências temporais, padrões de seme Ihanças e diferenças na sua distribuição, grupos mais af etados e mecanismos usados para perpe trar a agressão letal.

\section{Métodos}

Trata-se de um estudo epidemiológico descritivo da mortalidade por homicídios em países da América Latina (Argentina, Brasil, Colômbia e M éxico). Esses países foram selecionados por possuírem as mai ores populações da região e por apresentarem taxas variadas de mortalidade por homicídios ${ }^{12}$, além da disponibilidade dos dados e do interesse em participar do estudo.

As fontes dos dados de mortalidade foram a Dirección Nacional de Estadísticas e Información en Salud (DEIS-M SN) - Ministerio de Salud de Argentina; Sistema de Informações sobre M ortalidade (SIM ) - M inistério da Saúde do Brasil; Departamento Administrativo Nacional de Estadísticas (DANE) el nstituto Nacional de Medicina Legal y Ciencias Forenses (IN M LyCF) Colômbia; e Sistema Nacional de Información en Salud (SINAIS) dela Secretaría deSalud Fede ral - M éxico. As bases populacionais foram os censos e estimativas populacionais do Instituto Nacional de Estadística y Censos (INDEC) - Argentina; Instituto Brasileiro de Geografia e Estatística (IBGE) - Brasil; Departamento Administrativo Nacional de Estadísticas (DANE) - Colômbia; Centro Latinoamericano de Demografia (CELADE) e Instituto Nacional de Estadísticas, Geografía e Informática (INEGI) - M éxico.

As informações analisadas se referem a todos os óbitos por agressão, sob os códigos E800E999 da 9 a revisão da Classificação Internacional deDoenças/CID ${ }^{13}$ eseus correspondentes da CID 10ª revisã ${ }^{14}$, a partir de 1996, codificados como 
V01 a Y98 do capítulo XX, sob a denominação de causas externas. Os homicídios estão codificados como E960-E965.0; E965.4-E965.5; E965.9E968.3; E968.8-E969 pela 9ạ revisão da CID e com os códigos X85-X93; X95-X99; Y00-Y09; Y87.1 na 10 a revisão da CID.

Foram analisados os óbitos por causas externas e por homicídios em termos absolutos e frequências relativas, esegundo variáveis desexo, faixa etária e meio usado para perpetrar a agressão.

Para fins de comparação, as taxas de mortalidade foram ajustadas pelo método direto, tomando a população mundial padrão ${ }^{15}$. As taxas de mortes por homicídios da Argentina, ajustadas por idade, foram utilizadas como referência para o cál culo das razões de taxas de mortalidade dos demais países.

A tendência das taxas de mortalidade por homicídios nos grupos etários (0-9 anos, 10-14 anos, 15-19 anos, 20-29 anos, 30-39 anos, 40-49 anos, 50-59 anos e 60 ou mais anos) foi analisada através do modelo de regressão linear, considerando-se como variáveis dependentes as taxas de mortalidade de cada grupo etário e como variável independente os anos do período do estudo. Estabeleceu-se como significância estatística um $p$-valor $<0,05$. Considerou-se incremento da tendência temporal quando Beta maior que zero $(\beta>0)$ estatisticamente significativo ( $p$-valor $<0,05)$; decremento da tendência quando Beta menor de zero $(\beta<0)$ estatisticamente significativo ( $p$-valor $<0,05$ ) e tendência temporal estável quando o valor de Beta $(\beta)$ não foi estatisticamente significativo ( $p$-valor $\geq 0,05$ ).

$\mathrm{Na}$ análise dos dados foram usados os programasExcel 2003, SPSS versão 16 eo EPIDAT v3.1.

Por envolver o uso de dados secundários e de domínio público nos distintos países, cada grupo depesquisadores procedeu deacordo com as recomendações éticas requeridas por seu país. No Brasil, a proposta do estudo foi submetida ao Comitê de Ética em Pesquisa da Escola Nacional de Saúde Pública Sérgio Arouca/Fiocruz e aprovada.

\section{Resultados}

A Tabela 1 mostra as distintas características dos indicadores sociodemográficos dos países estudados. N ota-se que as populações do Brasil e do M éxico são bem maiores que as da Colômbia e daA rgentina. Grande parcela das populações desses países vive em área urbana, sendo que na Argentina esse percentual é o maior $(91,8 \%)$, enquanto na Colômbiaéo menor (74,2\%). Demodo geral, Argentina e M éxico apresentam indicadores como expectativa de vida ao nascer, Índice de Desenvolvimento H umano/IDH I Índice de Gini, média de anos de escolaridade dos adultos, taxa de analfabetismo para população acima de 15 anos e PIB per capita acima dos encontrados no Brasil, Colômbia e da média da América Latina. Isso posiciona os dois primeiros países nos 46‥ e 56ㅇ. lugares entreosI DH de169 países considerados pela UNESCO, enquanto Brasil e Colômbia se situam nas 73a e 79a posições, respectivamente. Valea pena destacar quea Colômbia aparece com a maior taxa de desemprego (10,3\% da força de trabalho) equeo Í ndice de Gini, quemedea desigualdade na distribuição de renda, aponta o Brasil $(0,56)$ e a Colômbia $(0,58)$ nas piores condições entre as áreas estudadas.

É importante ressaltar que embora o M éxico tenha a menor taxa de desemprego, possui uma elevada taxa de trabalho informal (cerca de 30\% da população economicamente ativa). Esse fe-

Tabela 1. Indicadores socioeconômicos e demográficos de países da América Latina - 2007

\begin{tabular}{|c|c|c|c|c|c|}
\hline Indicador & Argentina & Brasil & Colômbia & M éxico & América Latina \\
\hline Populaçãoa & 39.490 .465 & 190.119 .995 & 44.359 .445 & 105.280 .515 & 566.164 .103 \\
\hline População urbana (\%) & 91,8 & 85,1 & 74,2 & 76,9 & 78,2 \\
\hline Expectativa de vida ao nascer (anos) ${ }^{a}$ & 75,1 & 72,2 & 72,7 & 74,9 & 73,2 \\
\hline Índice de Desenvolvimento Humano ${ }^{b}$ & 0,764 & 0,685 & 0,676 & 0,742 & 0,698 \\
\hline Posição mundial (169 países) b & 46 & 73 & 79 & 56 & - \\
\hline Índice de Gini (2006) ${ }^{a}$ & 0,49 & 0,56 & 0,58 & 0,48 & - \\
\hline Anos de escolaridade dos adultos (média) & 9,0 & 6,8 & 7,0 & 8,2 & - \\
\hline Taxa de analfabetismo (\% acima de 15 anos) ${ }^{b}$ & 2,4 & 10,0 & 7,3 & 7,2 & - \\
\hline PIB per capita (US\$) a & 9.060 & 4.143 & 3.060 & 6.347 & 4.652 \\
\hline Crescimento do PIB (2006-2007) (\%) ${ }^{\mathrm{a}}$ & 8,2 & 5,7 & 7,2 & 3,2 & 5,5 \\
\hline Taxa de desemprego ( $\%$ da força de trabalho) ${ }^{a}$ & 8,5 & 8,1 & 10,3 & 3,4 & 7,1 \\
\hline
\end{tabular}

Fontes: (a) World Bank Data - World Development Indicators \& Global Development Finance. (b) UN ESCO - Institutefor Statistics. 
nômeno do crescimento do mercado informal detrabalho também éuma realidade nos demais países estudados.

Dados não apresentados para o período de 1990 a 2005 revelam ganhos na expectativa de vida, na taxa de alfabetismo de adultos, no PIB per capita real e no IDH dos quatro países estudados. 0 Brasil conseguiu aumentar em 6,1 anos sua expectativa de vida/EV, mas ainda é o país, entre os analisados, com o menor valor em relação a esseindicador ( 71,7 anos). Em seguida vem o M éxico (que a aumentou em 5,9 anos e passou a ter a maior EV - 75,6 anos, assumindo a primeira posição que era da Argentina no início do período analisado). N esse último país, o crescimento da EV foi de apenas 3,8 anos, próximos aos 3,5 anos ganhos na Colômbia nesse mesmo período. 0 Brasil também conseguiu aumentar, mais que os outros países, a sua taxa de alfabe tismo adulto: passou de $81,1 \%$ em 1990 para $88,6 \%$ em 2005, mas continua com a menor taxa em relação aos demais (Argentina 97,2\%, Colômbia $92,8 \%$, e M éxico 91,6\%). A Argentina começou e terminou o período com o maior IDH em relação aos países aqui comparados, o M éxico se manteve na segunda posição, mas o Brasi inverteu sua posição com a Colômbia passando da quarta para a terceira posição $0^{16-19}$.

Ao longo dos 18 anos investigados, as causas externas foram responsáveis nestes países por 4.086.216 ou 227.012 óbitos/ano em média eapre sentaram elevadas taxas de mortalidade (Tabela 2). 0 Brasil contabilizou mais de dois milhões de óbitos por causas externas de 1990 a 2007, valor sete vezes superior ao registrado na Argentina. $\mathrm{Na}$ Colômbia, a proporção decausas externasfoi igual a 23,3\% detodos os óbitos registrados no período; no Brasil eno México, essegrupo de causas correspondeu a $12,4 \%$ dos óbitos acumulados.
Entre 1990 e2007, a Argentinaapresentou uma elevação de $54,5 \%$ na taxa de mortalidade por causas externas, enquanto os demais países do estudo apresentaram uma diminuição (no Brasil de 8,1\%; na Colômbia de $31,8 \%$ eno M éxico de $37,0 \%$ ). A despeito da tendência de elevação na Argentina, esse país foi o que registrou a me nor taxa no período (28,2 óbitos por $100 \mathrm{mil}$ habitantes em 1995). A maior taxa de morte por causas externas foi observada na Colômbia em 1992 (125,1 óbitos por 100 mil habitantes).

No período analisado, foram registrados 1.432.971 homicídios nos quatro países aqui considerados, o que significa uma média anual de 79.609 homicídios/ano. A proporção de homicídios em relação ao grupo das causas externas apresentou grandevariabilidade: alcançou $60,7 \%$ na Colômbia, enquanto na Argentina foi igual a $11,5 \%$. As proporções no Brasil e M éxico foram $34,9 \%$ e $22,8 \%$, respectivamente.

A Figura 1 mostra a evolução das taxas ajustadas de mortalidade por homicídios nos países estudados. $\mathrm{Na}$ Argentina houve um aumento progressivo nas taxas de homicídios desde 1996, com um valor máximo em 2002 (7,4 por 100 mil habitantes), seguido de um decréscimo que re monta ao início da série. No Brasil as taxas aumentaram continuamente a partir de 1993. Em 2003 ela atingiu 26,8 por 100 mil habitantes, e seguiu-se um declínio com oscilações após 2003. Ao final do período esse país possuía uma taxa cerca de $9 \%$ superior à registrada em 1990, ape nas menor que a da Colômbia.

Ao longo de toda a série analisada a Colômbia apresenta as maiores taxas de homicídios. Em 1990, a taxa colombiana era 16,4 vezes maior que a taxa Argentina e evoluiu apresentando um pico de 1991 a 1993, seguido por um declínio até 1997. As taxas voltaram a subir no início dos

Tabela 2. Óbitos acumulados por Causas Externas (CE) em países da América Latina, 1990-2007

\begin{tabular}{lccccc}
\hline País & $\begin{array}{c}\text { \% de óbitos } \\
\text { acumulados por } \\
\text { CE }\end{array}$ & $\begin{array}{c}\text { CE em relação ao } \\
\text { total deóbitos }\end{array}$ & $\begin{array}{c}\text { Taxa bruta } \\
(100.000 \text { hab) } \\
\text { (média) }\end{array}$ & $\begin{array}{c}\text { Taxa ajustada } \\
(100.000 \text { hab) } \\
\text { (média) }\end{array}$ & $\begin{array}{c}\text { \% de } \\
\text { homicídios em } \\
\text { relação aos } \\
\text { óbitos por CE }\end{array}$ \\
\hline Argentina & 281.914 & 5,7 & 42,9 & 40,6 & 11,5 \\
Brasil & 2.057 .639 & 12,4 & 69,2 & 69,4 & 34,9 \\
Colômbia & 749.859 & 23,3 & 105,9 & 105,4 & 60,7 \\
M éxico & 996.804 & 12,4 & 57,4 & 61,6 & 22,8 \\
\hline
\end{tabular}

Fonte: Dirección Nacional de Estadísticas e Información en Salud (DEIS-M SN), M inisterio de Salud de Argentina. Sistema de Informações sobreM ortalidade (SI M ), M inistério da Saúde do Brasil. Departamento Administrativo N acional deEstadística (DANE) el nstituto N acional deM edicina Legal y Ciencias Forenses (IN M LyCF), Colômbia. Sistema Nacional del nformación en Salud (SINAIS) dela Secretaría de Salud Federal, M éxico. 
anos 2000 até al cançar o valor de 74,8 homicídios por 100 mil habitantes em 2002, caindo novamente até 0 final da série estudada. Em 2007, a Colômbia apresenta a taxa mais baixa do período (38,5 homicídiospor 100 mil habitantes) , cerca de $44 \%$ menor que a taxa de homicídios observada em 1990, mas ainda 8,9 vezes maior que a da Argentina.

O M éxico apresentou as maiores taxas de homicídios nos anos iniciais da década de 1990 (19,1 por 100 mil habitantes) com diminuição constante após 1992. Observa-se que depois de mais deuma década de declínio su cessivo, houve novo aumento das taxas em 2005 e 2006. 0 período fecha com nova queda e com a menor taxa observada. Entretanto, dados mais recentes indicam que essa tendência se inverteu ${ }^{20}$.

Nos sete primeiros anos do século XXI, as razões de mortalidade por homicídios ajustadas pela idade e tendo como referência a Argentina, com os respectivos intervalos de confiança de 95\% para ambos os sexos, foram de $4,4(3,8-5,1)$ no Brasil; 9,1 (8,3-9,9) na Colômbia e 1,6 (1,4$1,8)$ para o M éxico. Para a população masculina as razões foram de 4,7 (4,0-5,5) no Brasil; 9,8 (8,9-10,7) na Colômbia e 1,7 (1,4-1,9) no M éxico, e na população feminina foram iguais a 2,5
(2,3-2,7) no Brasil; 5,3 (4,6-6,1) na Colômbia e $1,4(1,3-1,5)$ no M éxico.

A evolução das taxas de homicídios segundo faixa etária esexo nosanos 1990, 2000 e 2007 apresentou comportamento distinto entre os países investigados (Figura 2). Tendo em vista a falta de espaço, os dados relativos a esta análise não serão mostrados em tabela. Na Argentina, os homens com faixa etária de 20-29 anos (14,5) easmulheres com idade superior a 60 anos $(2,2)$ foram os grupos com as maiores taxas em 2007. Os indivíduos do sexo masculino com idade entre 15-39 anos e acima de 60 anos, juntamente com a população feminina com até 9 anos, entre 15- 19 anos e de 4049 anos apresentaram crescimento não constante nas taxas de homicídios ( $\beta>0$; $p$-valor $<0,05$ ).

No período estudado, o Brasil apresentou crescimento da taxa de mortalidade por homicídios em todos os grupos etários. Observam-se as maiores taxas na faixa dos 20-29 anos, tanto para homens quanto para mulheres - 100,4 e 6,6 ao fim do período, respectivamente. Sendo que na faixa etária de 10-29 anos para ambos os sexos, acima de 60 anos para o sexo masculino e no grupo de 50-59 anos do sexo feminino este aumento foi estatisticamentesignificativo $(\beta>0$; p-valor $<0,05)$.

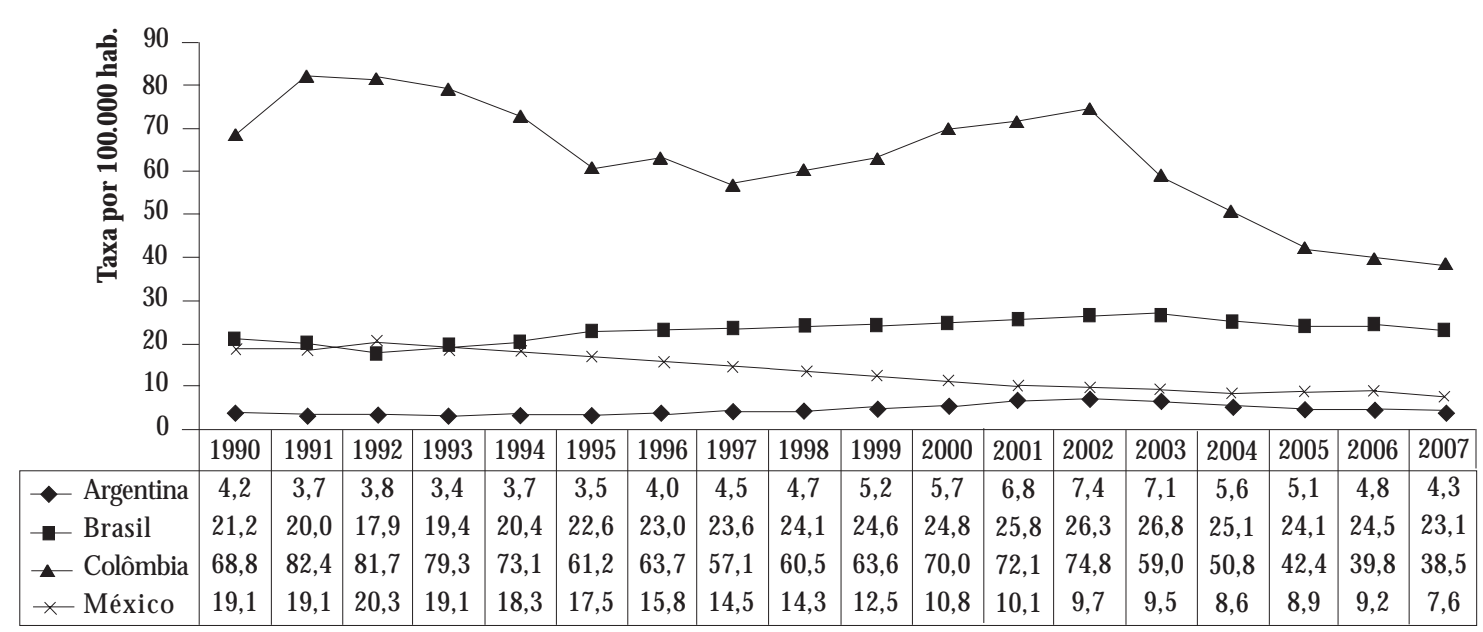

Figura 1. Evolução das taxas de mortalidade por homicídios, ajustadas por idade, em países da América Latina, 1990-2007

Fonte: Dirección N acional deEstadísticas el nformación en Salud (DEIS-M SN), M inisterio de Salud deArgentina. Sistema de Informações sobre M ortalidade(SI M ), M inistério da Saúde do Brasil. Departamento Administrativo N acional de Estadística (DANE) eInstituto N acional de M edicina Legal y Ciencias Forenses (IN M LyCF), Colômbia. Sistema N acional de Información en Salud (SIN AIS) de la Secretaría de Salud Federal, M éxico. 
As taxas de homicídios na Colômbia registraram queda em todas as faixas etárias de ambos os sexos. Considerando-se o ano inicial e 0 final do período estudado, as taxas na faixa etária de 20-29 anos sofreram um decréscimo de aproximadamente $42 \%$ parahomens e $35 \%$ para mulheres. Reduções estatisticamente significativas $(\beta<0$; $p$-valor $<0,05)$ foram encontradas para o sexo masculino nos grupos acima dos 15 anos, e para o sexo feminino nos grupos entre 10-39 anos e acima de 60 anos.

No M éxico, as taxas mais baixas, para ambos os sexos, foram observadas nos menores de 15 anos (sexo masculino: 0,9 e 1,3; sexo feminino: 0,8 e 0,7 , no fim do período). No caso dos homens, as taxas mais elevadas são observadas no grupo entre 30-39 anos $(25,2)$, seguida por aqueles com idade entre 20-29 (21,5) e 40-49 anos $(24,0)$. N a população feminina foram encontradas as maiores taxas $(2,8)$ na faixa etária acima de 60 anos. Todas as faixas etárias, em ambos os sexos, registraram tendência decrescente nas taxas de homicídios ( $\beta<0$; $p$-valor $<0,05$ ).

A análise da distribuição percentual dos homicídios segundo os meios utilizados para perpetrá-los (Tabela 3) mostra que na Argentina as armas de fogo são mais utilizadas para a execução de homicídios, seguidas pelos objetos cortantes ou penetrantes. Dentre os demais mecanismos com baixas proporções, destaca-se 0 enforcamento, o estrangulamento e a sufocação. Cabe ressaltar que o grupo dos homicídios por

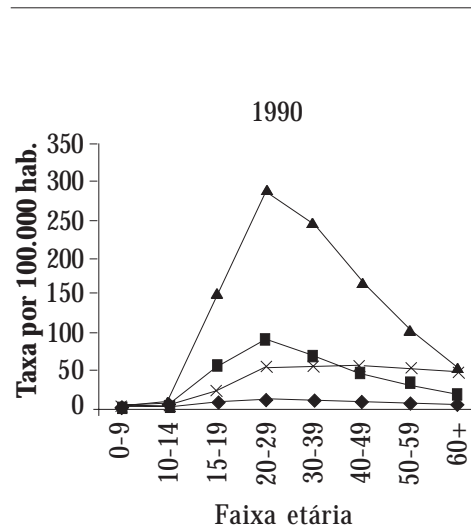

Faixa etária

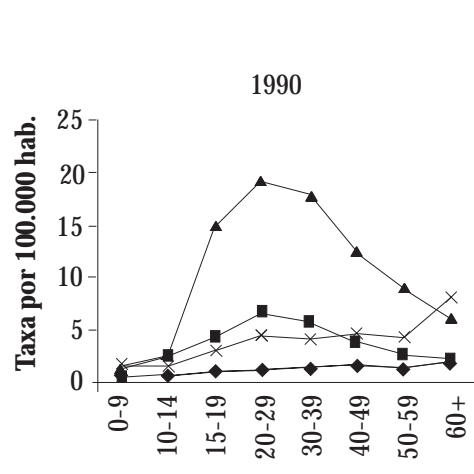

Faixa etária

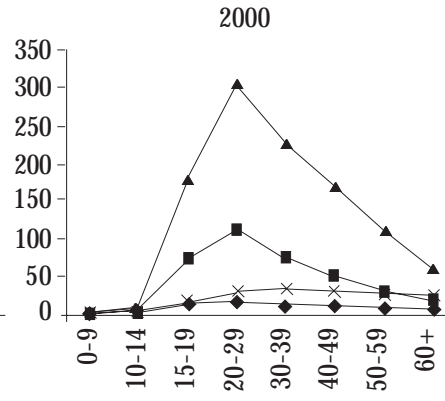

Faixa etária

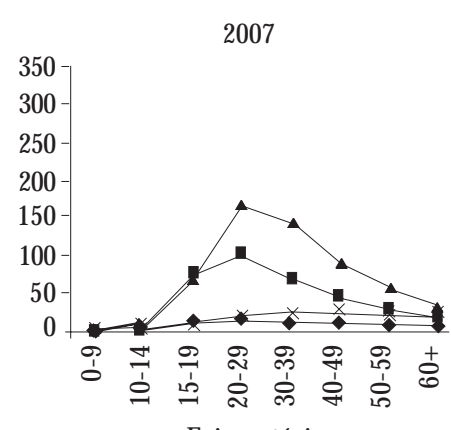

Faixa etária

Feminino

2000

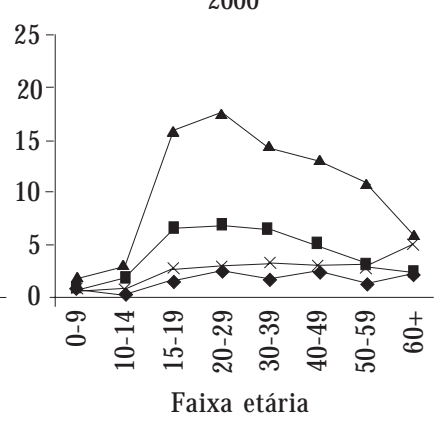

- Argentina

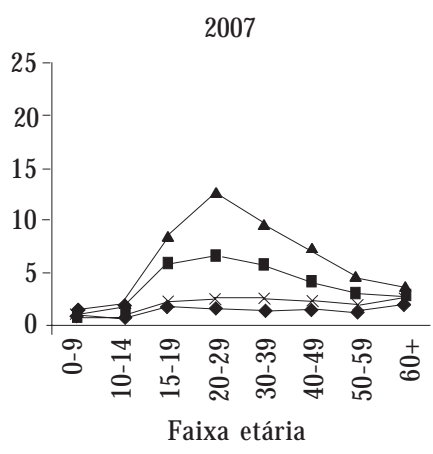

Figura 2. Taxas de mortalidade por homicídios por idade e sexo em países da América Latina - 1990, 2000 e 2007

Fonte: Dirección N acional de Estadísticas eInformación en Salud (DEIS-M SN ), M inisterio de Salud deArgentina. Sistema de Informações sobre M ortalidade (SI M ), M inistério da Saúde do Brasil. Departamento Administrativo Nacional de Estadística (DANE) el nstituto N acional de M edicina Legal y Ciencias Forenses (IN M LyCF), Colômbia. Sistema Nacional de Información en Salud (SINAIS) de la Secretaría de Salud Federal, M éxico. 
Tabela 3. Distribuição percentual dos homicídios por meio utilizado em países da América Latina - 1990, 2000 e 2007

\begin{tabular}{|c|c|c|c|c|c|c|c|c|c|c|c|c|}
\hline \multirow[b]{2}{*}{ Descrição } & \multicolumn{3}{|c|}{ Argentina } & \multicolumn{3}{|c|}{ Brasil } & \multicolumn{3}{|c|}{ Colômbia } & \multicolumn{3}{|c|}{ México } \\
\hline & 1990 & 2000 & 2007 & 1990 & 2000 & 2007 & 1990 & 2000 & 2007 & 1990 & 2000 & 2007 \\
\hline Afogamento e submersão & 1,6 & 0,2 & 0,2 & 0,1 & 0,1 & 0,1 & 0,1 & 0,1 & 0,1 & 1,9 & 1,9 & 1,0 \\
\hline Substâncias corrosivas & 0,0 & 0,0 & 0,0 & 0,0 & 0,0 & 0,0 & 0.0 & 0.0 & 0.0 & 0,0 & 0,0 & 0,0 \\
\hline Armas de fogo & 49,5 & 58,2 & 43,5 & 50,6 & 68,1 & 71,9 & 83,3 & 85,0 & 78,5 & 52,1 & 50,7 & 56,8 \\
\hline Enforcamento, estrangulamento e sufocação & 2,8 & 4,2 & 3,9 & 1,1 & 1,0 & 1,3 & 0,5 & 0,8 & 1,4 & 2,3 & 6,2 & 6,5 \\
\hline Envenenamento & 0,1 & 0,1 & 0,1 & 0,0 & 0,0 & 0,0 & 0,1 & 0,0 & 0,1 & 0,7 & 0,3 & 0,2 \\
\hline Fumaça, fogo e chamas & 0,4 & 0,3 & 0,6 & 0,2 & 0,2 & 0,3 & 0,1 & 0,1 & 1,2 & 0,5 & 0,6 & 0,5 \\
\hline Material explosivo & 0,8 & 0,1 & 0,1 & 0,9 & 0,0 & 0,0 & 0,7 & 0,6 & 1,3 & 0,1 & 0,1 & 0,0 \\
\hline Objeto contundente & 1,2 & 0,8 & 2,6 & 3,5 & 4,5 & 5,0 & 0,9 & 0,9 & 1,5 & 1,8 & 1,4 & 1,5 \\
\hline Objeto cortante ou penetrante & 21,3 & 20,6 & 31,5 & 16,9 & 12,4 & 15,4 & 14,6 & 11.2 & 15,7 & 16,0 & 16,5 & 16,7 \\
\hline Projeção de um lugar elevado & 0,1 & 0,0 & 0,1 & 0,0 & 0,0 & 0,0 & 0,0 & 0,0 & 0,0 & 0,1 & 1,2 & 0,4 \\
\hline Seqüelas de uma agressão & 0,0 & 0,0 & 0,1 & 0,0 & 0,0 & 0,1 & 0,0 & 0,0 & 0,0 & 0,0 & 0,1 & 0,0 \\
\hline Sexual ou por força física & 1,4 & 0,7 & 1,0 & 0,3 & 0,6 & 1,0 & 0.0 & 0.0 & 0.1 & 0,7 & 1,3 & 1,4 \\
\hline Outros meios especificados & 0,9 & 0,9 & 1,6 & 0,3 & 1,3 & 1,1 & 0,1 & 0,2 & 0,2 & 0,5 & 3,4 & 1,7 \\
\hline M eio não especificado & 21,5 & 13,7 & 14,5 & 26,2 & 11,8 & 3,8 & 2,7 & 1,0 & 1,0 & 23,1 & 16,2 & 13,1 \\
\hline
\end{tabular}

Fonte: Dirección N acional de Estadísticas e Información en Salud (DEIS-M SN) , M inisterio de Salud de Argentina. Sistema de I nformações sobre M ortalidade(SIM ), M inistério da Saúde do Brasil. Departamento Administrativo Nacional deEstadística (DANE) elnstituto Nacional de M edicina Legal y Ciencias Forenses (IN M LyCF), Colômbia. Sistema Nacional de Información en Salud (SIN AIS) dela Secretaría de Salud Federal, M éxico.

meios não especificados representou a segunda maior proporção em 1990, caiu em 2000 e apresentou uma elevação no final do período.

No Brasil percebe-se tendência crescente de uso das armas de fogo como principal meio. Em 1990, elas representavam 50,6\% dos óbitos por homicídios; em 2007 esta proporção elevou-se para $71,9 \%$. Em 2007, o uso de objeto cortante ou penetrante para o cometimento de homicídios foi o segundo meio mais utilizado. É possível que parte do crescimento desses grupos maisfrequentes se deva à diminuição dos homicídioscujo meio não foi especificado, ou seja, ao melhor esclarecimento dessa informação.

$\mathrm{Na}$ Colômbia, as armas defogo além de constituírem o meio mais utilizado para o cometimento de homicídios, abrangem mais de três quartos deles, mesmo com o declínio observado ao longo da série estudada. 0 segundo foi o uso de objeto cortante ou penetrante, cuja proporção cresceu atingindo 15,7\% em 2007. O s homicídios cometidos por meios não especificados, que no início da série apresentavam uma proporção de $2,7 \%$ reduziram para $1,0 \%$ no fim do período analisado, indicando bom esclarecimento dessa informação.

No M éxico, mais da metade dos homicídios foram perpetrados com o uso de armas de fogo com crescimento dessa proporção em 2007, quando alcança cerca de $57 \%$. O shomicídios cometidos com objeto cortante ou penetrante mantiveram a mesma proporção no período do estudo ( $16 \%$ a 16,7\%). Os homicídios por enforcamento, estrangulamento e sufocação triplicaram no período, ao passo que o grupo dos homicídios cometidos por meios não especificados, apresentaram redução, passando de 23\% em 1990, para 13\% em 2007.

\section{Discussão}

A América Latina pode ser caracterizada como uma região cujos países possuem grandes diferençassocioeconômicas, políticas eculturais, mas também têm grandes semelhanças, demonstradas nos indicadores socioeconômicos e demográficos aqui apresentados. Tais características devem ser levadas em consideração para uma melhor compreensão dos elevados índices de homicídios na região.

Os dados analisados mostram que os países apresentam em comum elevadas taxas de homicídios, exceto a Argentina, cujas taxas são intermediárias se comparadas com países de outras regiões; o decréscimo das taxas a partir do ano de 2003; a maior incidência entre os jovens do sexo masculino e o uso das armas de fogo para perpetrar os homicídios, que alcança extrema intensidade na Colômbia. Por outro lado diferem quanto às taxas, que são elevadíssimas na 
Colômbia e se sobrepõem aos demais países, se guidas pelas do Brasil, em contraposição às menores da Argentina. $N$ ão é por acaso que os dois primeiros países possuem os piores indicadores e o último mostra melhores condições socioeconômicas e demográficas. A associação entre as determinações sociais e os índices de violência tem sido demonstrada em vários estudos ${ }^{1}$.

I mporta ressaltar que as taxas seriam ainda mais elevadas se houvesse melhor qualidade da informação relativa aos óbitos por esta causa nos países em questão. É conhecido o sub-registro dos homicídios, dentre outras coisas pelas dificuldades de esclarecimento da causa básica do óbito, o que implica no crescimento proporcional do grupo específico de mortes que se ignora se acidental ou intencionalmente infligidas, da Classificação Internacional de Doenças/CID 10.

No entanto, é preciso ter em mente as complexas e múltiplas determinações dos homicídios não só no que se refere às questões macro políticas e macro econômicas que afetam os países da região, mas também atentar para as especificidades com que tais políticas são implantadas e implementadas no âmbito de cada país. As distinções culturais que os conformaram no passado e atuam no presente também jogam um peso nas explicações da violência. Estudos buscam compreender a violência a partir dosfatores que a originam, fomentam efacilitam, recorrendo às distintas teorias sociológicas ${ }^{21}$.

A Colômbia vive uma situação de violência generalizada em que relacionamentos violentos estão na base dos conflitos nas áreas da vida privada, da família, da vida pública e das interações políticas, do trabalho e até dos esportes 22,23 . H istoricamente o primeiro ciclo de escalada dos homicídios ocorreu entre 1950 einício dosanos 1960 quando as taxas de homicídios partiram de 10 homicídios/100 mil hab. em 1946, para50/100 mil hab. em 1957. Um acordo político resultou no declínio desta taxa, chegando a 20/100 mil hab. no final dos anos 60 . Na década de 1980, ocorreu um crescimento acelerado nas taxas dehomicídio que levaram a um segundo ciclo de violência intensa, quepermaneceatérecentemente. A taxa de homicídios aumentou rapidamente para chegar a um pico de 81/100 mil hab. em 1991. Desde então, embora tenham diminuído, as elevadas taxas coincidem com a consolidação e o fortalecimento dos grupos guerrilheiros e paramilitares. Três fenômenos estão relacionados com 0 atual ciclo de violência no país: o narcotráfico (produção, processamento, circulação e consumo de substâncias psicoativas ilegais); o conflito políti- co-militar, que inicialmente envolveu as guerriIhas e as forças armadas estatais e posteriormente as organizações paramilitares e o conjunto da sociedade civil. Em terceiro lugar, tem papel importante o desenvolvimento e a consolidação do modelo econômico edeconcepção do Estado, globalmente conhecido como neoliberalismo. A análise da relação dessas três situaç̧̃̃es com a violência é fundamental para a compreensão do contexto e dos assassinatos na Colômbia.

o Brasil, após décadas de crescimento ininterrupto das taxas de homicídios começa a apre sentar um declínio deste índice. Alguns fatores que podem ajudar a entender esse declínio são 0 sucesso de políticas públicas mais amplas, conforme pode ser visto nos indicadores aqui apre sentados, mas também de políticas específicas, sobretudo em estados com grande peso demográfico, o que incide diretamente sobre as taxas nacionais, como o Estatuto do Desarmamento $0^{24,25}$ e a campanha do desarmamento em 2004, que retirou muitas armas de circulação ${ }^{26}$. Em oposição a esta tendência de queda sistemática para o conjunto do país, um fenômeno denominado interiorização da violência fez com que cidades da região Nordeste e municípios das regiões me tropolitanas e do interior dos Estados passassem a apresentar taxas mai ores que as encontradas na região Sudestee nas capitais dos Estados ${ }^{6}$.

No M éxico, as maiores taxas de homicídios são encontradas em alguns estados localizados no N orte e N oroeste do país. Neles, além da pre sença dos grandes cartéis das drogas e a proximidade com afronteira americana, também ocorre o comércio ilegal de armas e as taxas de homicídio de jovens são maiores. 0 desemprego e a falta de vagas no sistema educacional, especialmente entre a população de 15-29 anos, criam a possibilidade desses jovens serem cooptados pe las redes do crime organizado 27,28 .

A Argentina éo país com as menores taxas de homicídios e, não por acaso, com os melhores indicadores sociodemográficos, conforme ficou evidentenos dados apresentados. Entretanto, no período focalizado vários estudos apontam o crescimento dessa forma de violência nos anos próximos à crise gerada pelos ajustes econômicos que abalou aquele país no início dos anos 200029,30. Alguns dos dados aqui apresentados (incremento das taxas de homicídios nos anos 2000 a 2002 e da proporção do uso de armas de fogo para cometêlos) são reflexo desse período de turbulência econômica, política e social.

Os achados desta pesquisa revelam que énos adolescentes enos jovens do sexo masculino que 
incidem as maiores taxas dehomicídio, evidenciando a necessidade de priorizar esses grupos nas políticas públicas de atenção e prevenção dos diversos setores sociais. Para buscar compreender o envolvimento dos homens com a violência, estudos se apropriam da noção de uma masculinidade calcada na agressividade e no uso da força para a resolução de divergências e conflitos ${ }^{31}$. Nos anosnoventa, os al tosíndices de mortalidade por violência entrehomensjovens naAmérica Latina e Caribe intensificaram o debate sobre a relação homem-violência32. Cerca de um a cada dois homensjá experimentou al guma situação deagressão física ${ }^{33}$. N o que se refere particularmente aos homicídios no Brasil, em 2008, 92,0\% das vítimas são homens4. Também são os homens jovens os principais autores desses homicídios.

Do mesmo modo, o uso das armas de fogo também podeser explicado pelasimbologia masculina que tem esses instrumentos e por sua associação com o poder de vida ou morte ${ }^{34}$. Esse objeto é, desde cedo, introduzido na vida do menino sob a forma de brinquedo, passando posteriormente a fazer parteinerenteao universo masculino. A pesar das leis que restringem o comércio e o porte de armas de fogo, o contrabando facilitado pela falta de fiscalização das fronteiras permite acesso fácil e o uso das mesmas para a execução de homicídios.

Os problemas existentes nas fronteiras desses países ultrapassam as questões relativas ao tráfico de armas e drogas. N essas áreas existe ainda o contrabando de outras mercadorias, como pedras preciosas, e os conflitos entre fronteiras agrícolas e pela posse da terra que também fomentam taxas el evadas de homicídios ${ }^{35}$.

Estes e muitos outros fatores poderiam ser elencados para ajudar na compreensão de tantas mortes por agressão, como a corrupção e a impunidade, bem como outras complexas questões que o espaço deste artigo não permite que sejam discutidas.

No entanto, fica clara a necessidade de rever as políticas vigentes deenfrentamento da violên- cia, no sentido detornar viável o estabelecimento deestratégias que estimulem a integração eo protagonismo dos principais atores e vítimas desse processo (adolescentes e jovens) e que articulem amplos setores da sociedade, possibilitando a inserção de amplas camadas populacionais que se encontram alijadas dos direitos fundamentais previstos nos regimes democráticos. Em outras palavras, a região precisa ampliar e consolidar sua democracia e os direitos de cidadania a todos os seus habitantes, a fim de reduzir seus inaceitáveisíndices deviolência.

Para finalizar, al gumas limitações do presente estudo são discutidas. A utilização do modelo de regressão linear na análise dos dados impõe certas restrições, tendo em vista que esse modelo pressupõeindependência das observações, exigência que nem sempre é atendida pelos dados de séries temporais. Essa técnica pode mostrar significância estatística quando na realidadeisso não ocorre. Ou seja, se as observações são dependentes, a variabilidade do valor Beta ( $\beta$ ) pode ser maior quea estimada pel o modelo eserão encontrados valores estatisticamente significativos que não o são. Isto ocorre porque a estimação das variâncias foi alterada ao não se considerar a independência do dado. A forma como o modelo foi apresentado, com o objetivo de facilitar a compreensão, tem a limitação de não distinguir a magnitude do valor de Beta ( $\beta$ ). Assim, qualquer valor de Beta $(\beta)$ maior ou menor quezero mostraria uma tendência de aumento ou de diminuição, mas se o valor for de uma magnitude muito pequena não é possível verificar uma tendência temporal claramente definida. Desse modo, as análises de tendências aqui realizadas precisam ser relativizadas. Também não se considerou 0 ano centralizado, pel o fato deal guns autores descartarem esse tipo de análise ${ }^{36}$ quando a dispersão das taxas de mortalidade dos grupos etários e anos do período analisado demonstram que uma evolução linear pode ser assumida, conforme ocorreu com os dados aqui apresentados. 


\section{Colaboradores}

ER Souza, AN M elo, JG Silva, SA Franco, M Alazraqui e GJ González-Pérez participaram igualmente de todas as etapas de elaboração do artigo.

\section{Agradecimentos}

Ao CN Pq pelo apoio dado ao estudo multicêntrico, por meio do IN CT Violência, Democracia e Segurança Cidadã, que possibilitou o encontro e debate entre os grupos de pesquisadores. A todos os membros das equipes de cada país que contribuíram de forma direta ou indireta para a realização deste estudo.

\section{Referências}

1. United Nations Office on Drugs and Crime (UNODC). The 2001 Global Study on Homicide. Vienna: UNODC; 2011.

2. Krug E. Relatório mundial sobre violência e saúde Genebra: Organização M undial da Saúde (OMS); 2002.

3. World Health Organization (WHO). Death and Disability Adjusted Life Years (DALY) estimates for 2002 by cause for WHO member states. Department of M easurement and Health Information. [Document da Internet]. [acessado $2011 \mathrm{abr}$ 3]. Disponível em: http://www.who.int/healthinfo/bod/en/index.html.

4. Waiselfisz JJ. Mapa da Violência 2011: os jovens do Brasil. São Paulo: Instituto Sangari, M inistério da Justiça; 2011.

5. Waiselfisz JJ. Mapa da Violência: os jovens da Amé rica Latina 2008. São Paulo: Instituto Sangari, M inistério da Justiça; 2008.

6. Souza ER, Lima M LC, Bezerra EAD. Homicides in Brazil: Evolution and Impacts. In: Lovisi GM, Mari JJ, Valencia ES, editors. The Psycological Impact of Living under violence and poverty in Brazil. New York: Nova Science Publishers Inc; 2010.

7. Organización Panamericana de la Salud (OPS). Informe mundial sobre la violencia y la salud. Washington, DC: OPS, OM S; 2003. (Publicación científica y técnica, n.588).

8. Saín M. Recuperación y destrucción de armas en circulación ilícita. Proyecto Construyendo Seguridad Ciudadana del Programa de Apoyo a la Reforma Estatal y Fortalecimiento Fiscal. Informe de Avance 1 y 22003

9. Cardona M, García HI, Giraldo CA, López MV Suárez CM, Corcho DC, Posada CH, Flórez MB. Homicidios en Medellín, Colombia, entre 1990 y 2002: actores, móviles y circunstancias. Cad Saude Publica 2005; 21(3):840-851.

10. Franco $\mathrm{S}$. La violencia homicida y su impacto sobre la salud en América Latina. In: M inayo MCS, Coimbra Júnior CEA, organizadoras. Críticas e Atuantes. Ciências Sociais e Humanas em Saúde na América Latina. Rio de Janeiro: Fiocruz; 2005. p. 619-635.

11. Peres M FT, Santos PC. M ortalidade por homicídios no Brasil na década de 90: o papel das armas de fogo. Rev Saude Publica 2005; 39(1):58-66.

12. Organização Panamericana de Saúde (OPAS). Información y análisis de salud: situación de salud en las Americas: indicadores básicos 2009. Washington, DC: OPAS; 2009

13. Organização M undial da Saúde (OMS). M anual da classificação estatística internacional de doenças, lesões e causa de óbitos. N ona revisão, 1975. São Paulo: Centro de Classificações de Doenças em Português; 1978.

14. Organização M undial da Saúde (OMS). Classificação estatística internacional de doenças e problemas re lacionados à saúde. Décima revisão. São Paulo: Centro de Classificação de Doenças em Português; 1996. 
15. World Health Organization (WHO). World health statistics annual - 1996. Geneva: WHO; 1996.

16. Programa de las Naciones Unidas para el Desarrollo (PNUD). Informe sobre desarrollo humano 1993: Participación popular. Centro de Comunicación, Investigación y Documentación entre Europa, España y América Latina (CIDEAL). M adrid: PNUD; 1993.

17. United Nations Development Programme (UNDP). Human Development Report 1998. New York, Oxford: Oxford University Press; 1998.

18. Programa de las Naciones Unidas para el DesarroIlo (PNUD). Informe sobre Desarrollo Humano 2002: profundizar la democracia en un mundo fragmentado. Nova York: Ediciones Mundi-Prensa; 2002.

19. Programa de La Naciones Unidas para el DesarroIlo (PNUD). Informe sobre Desarrollo H umano 20072008. La lucha contra el cambio climático: Solidaridad frente a un mundo dividido. Nova York: Ediciones M undi-Prensa; 2007.

20. Escalante-Gonzalbo F. Homicidios 208-2009 La muerte tiene permiso. $\mathrm{N}$ exos 2011; 397.

21. Briceño-León R. U rban violence and public health in Latin America: a sociological explanatory framework. Cad Saude Publica 2005; 21(6):1629-1664.

22. Franco S, Suárez C, Naranjo C, Baez L, Rozo, P. The effects of de armed conflict on the life and health in Colombia. Cien Saude Colet 2006; 11(2):349-361.

23. Franco S. El quinto no matar. Bogotá: Tercer Mundo Editores; 1999.

24. Brasil. Lei 10.826/2003. Estatuto do desarmamento. Dispõe sobre registro, posse e comercialização de armas de fogo e munição, sobre o Sistema Nacional de Armas - Sinarm, define crimes e dá outras providências. Diário Oficial da União 1990; 22 dez.

25. Peres M FT, Vicentin D, Nery M B, Lima RS, Souza ER, Cerda M, Cardia N, Adorno S. Queda dos homicídios em São Paulo, Brasil: uma análise descritiva. Rev Panam Salud Publica [periódico na Internet]. 2011 jan. [acessado 2012 ago 12]; 29(1):17-26. Disponível em: http://www.scielosp.org/pdf/rpsp/ v29n1/03.pdf

26. Souza M FM, Macinko J, Alencar AP, Malta DC, de $\mathrm{M}$ orais $\mathrm{N}$ eto $\mathrm{OL}$. Reductions in firearm-related mortality and hospitalizations in Brazil after gun control. Health Aff (M illwood) 2007; 26(1):575-584.

27. González-Pérez GJ, Vega-López M G, Vega-López A, Muñoz-De-La-Torre A, Cabrera-Pivaral CE. Homicidios de adolescentes en M éxico, 1979-2005: evolución y variaciones sociogeográficas. Papeles de Población 2009; 15(62):109-141.

28. Organización para la Cooperación y el Desarrollo Económico (OCDE). Panorama de la Educación 2011. [documento da Internet]. 2011 [acessado 2011 nov 10]. Disponível em: http://www.oecd.org/dataoecd/32/32/48667648.pdf.
29. Spinelli $\mathrm{H}$, Alazraqui $\mathrm{M}$, Zunino $\mathrm{G}$, Olaeta $\mathrm{H}$, Poggese $\mathrm{H}$, Concaro $\mathrm{C}$, Porterie $\mathrm{S}$. Mortes e crimes cometidos com armas de fogo na cidade autônoma de Buenos Aires, 2002. Cien Saude Colet 2006; 11(2): 327-338.

30. Zunino M G, Souza ER. La mortalidad por armas de fuego en Argentina entre 1990 y 2008. Cad Saude Publica 2012; 28(4):665-677.

31. Keijzer B. Hasta donde el cuerpo aguante: género, cuerpo y salud masculina. In: Cáceres C, Cueto $M$, Ramos M, Vallens S, organizados. La salud como derecho ciudadano: perspectivas y propuestas desde América Latina. Lima: Facultad de Salud Pública y Administración de la Universidad Peruana Cayetano Herida; 2003. p.137-152.

32. Couto MT, Schraiber LB. Homens, saúde e violência: novas questões de gênero no campo da saúde coletiva. In: Minayo MCS, Coimbra Júnior CEA, organizadores. Críticas e Atuantes. Ciências Sociais e Humanas em Saúde na América Latina. Rio de Janeiro: Fiocruz; 2005. p. 687-706.

33. Schraiber LB, Gomes R, Couto MT. Homens na pauta da saúde coletiva. Cien Saude Colet 2005; 10(1): 7-17.

34. Souza ER. Masculinidade e violência no Brasil: contribuições para a reflexão no campo da saúde. Cien Saude Colet 2005; 10(1):59-70.

35. Reichenheim ME, Souza ER, M oraes $C L$, M ello Jorge MHP, Silva CM FP, M inayo MCS. Violence and injuries in Brazil: the effect, progress made, and challenges ahead. The Lancet 2011; 377(9781): 1962-1975.

36. Silva GA, Gamarra CJ, Girianelli VR, Valente JG.Tendência da mortalidade por câncer nas capitais e interior do Brasil entre 1980 e 2006. Rev Saude Publica 2011; 45(6):1009-1018.

Artigo apresentado em 10/05/2012 Aprovado em 23/07/2012

Versão final apresentada em 13/09/2012 